\title{
DESIGN, AND MANUFACTURING A SMALL-SCALE WIND TUNNEL FOR HEAT TRANSFER ANALYSIS OF FLAT PLATE AND FINNED PLATE HEAT SINKS
}

\author{
ARKAN F. SAEED ${ }^{1}$ and ODAY A. ABBo \\ Dept. of Mechanical Engineering, College of Engineering, University of Duhok, \\ Kurdistan Region-Iraq
}

(Accepted for Publication: December 8, 2020)

\begin{abstract}
Application that utilize heat sinks for cooling electrical devices have been increased significantly during the last decade. In present work, the design and installation of small-scale wind tunnel have been executed. An experimental analysis of flow over a flat plat combined with constant heat flux have been investigated to ensure the effectiveness of the device. The design satisfied the basic equations of fluid flow to get the required laminar flow before the test section. The calculations depend on the change in heat flux across the flat plate and obtained results are compared with the previous published results for validation. Experimental analysis of constant heat flux from a horizontal rectangular fin array (HRFA) under controlled forced convection heat loss. The characteristics are investigated for fin with $L / H=1.416$; the effect of various parameters such as heater input with different fluid flow velocity on average heat transfer coefficient $(h)$ have been studied. The dimensionless number analysis like Nusselt number $(\mathrm{Nu})$, Reynolds number $(R e)$, were investigated. The heat transfer from surface may, generally, be enhanced by increasing the coefficient of heat transfer between a surface and its surrounding, or by increasing the area of heat transfer surface. An empirical correlations have been differentiated relating Nusselt and Reynolds numbers for both flat plate heat sink with the range $9.3 \times 10^{3} \leq R e \leq 19.1 \times 10^{3}$, and $\operatorname{Pr}<1.0$ with a total error $\pm 5 \%$, and finned plate heat sink with the range $7 \times 10^{3} \leq R e \leq 22.5 \times 10^{3}$, and $P r<1.0$ with a total error $\pm 6.4 \%$.
\end{abstract}

KEYWORDS: Heat Transfer enhancement, Finned plate heat exchanger, Flat plate convection.

\section{INTRODUCTION}

$\mathbf{F}$ luid stream inside mini or scaled down channels is at the point of convergence of the distinctive trademark and man-made structures. Heat and mass transfer is developed over the occupy dividers in regular structures, like the cerebrum, lungs, kidneys, intestines, blood vessels, etc., also as in many man-made systems, like heat exchangers, desalination units, nuclear reactors, and air separation units.

As a rule, the exchange forms happen over the channel dividers, while the greater part arkan.alhazeen@uod.ac; stream happens through the cross-sectional region of the channel. The channel cross-segment along these lines is a conductor to move liquid to and faraway from the channel dividers.

A channel serves to achieve two destinations: (i) carry a liquid into private contact with the channel dividers and (ii) carry new liquid to the dividers and deduct fluid removed from the dividers that the transport procedure is cultivated. The procedure of transport speed relies upon the area, which changes with the diameter $D$ for a round cylinder, though the pace of stream relies oday.adnan@uod.ac

${ }^{1}$ Corresponding author: College of Engineering, University of Duhok, Kurdistan Region, Iraq. 
upon the cross-sectional area, which varies straightly with $D_{h}$. Along these lines, the cylinder area to volume ratio changes as $1 / D$. Unmistakably, as the diameter diminishes, surface area to volume proportion increments [Satish G. Kandlikar, et. al., (2006)].

Microchannel heat sink presented in mid 1980s by Tuckerman and Pease, can improve single-stage heat remove rate altogether contrasted with the conventional channel by expanding surface area to volume proportion and diminishing convective heat transfer thermal reluctance, their spearheading work has propelled numerous specialists to focus on the subject and miniaturized scale channel stream has been perceived as a superior heat expulsion instrument from that point onward [Bahrami, M. et. al., (2006)].

Anyway dispersal of expanded heating load in single-stage convective stream in micro-channel is limited by its cost, high pressure drop and high temperature gradient along the stream heading and here and there become illogical to actualize. Fluid and thermal performance for smaller scale channel heat sinks are frequently demonstrated with Reynolds numbers, evident friction factors, Nusselt numbers, and boundaries that depict the thermal and fluid performance of the coolant. The thermal performance depends, to some extent, on whether the coolant stream is laminar or turbulent. The Reynolds number, Re, which is the proportion of inertial to viscous fluid forces, used to gauge the progress among laminar and turbulent flow [Mahgoub, S. E. (2013)].

The flow elements and heat transport properties of a mini scale channel heat-sink were examined numerically. The key discoveries from the investigation are Pressure drop increments with increment in Reynolds number and pressure drop along the channel is linear with the supposition of constant viscosity. Greatest temperature inside the heat sink is experienced at the base of the sink promptly beneath the arkan.alhazeen@uod.ac; channel outlet. Temperature of the heat sink can be diminished by expanding the flow rate of coolant. The heat flux and Nusselt number is far higher close to the channel gulf and fluctuates around the channel outskirts moving toward zero at the sides of rectangular miniaturized scale channel. [Md. Emran and Mohammad A.Islam, (2014)]

Vedulla Manoj Kumar, Sk. Farooq, and B Nageswara Rao (2016), works summing up an expository examination of different parts of heat transfer amelioration by the utilization of micro-channel heat sink. Results: A survey is introduced for deciding ideal micro-channel conductor conditions by the thought of both heat transfer qualities and fluid elements. The audit examined about the conceivable future headings of exploration that might be followed so as to get more noteworthy comprehension of micro-channel heat sinks.

The purpose of the present work is to introduce an experimental rig with a test section to seek the thermal behavior across a heat-sink prototype that can be used in electronics cooling. The design calculations depended on change in heat flux across the flat plate and the gained results are compared with the theoretical results. The heat transfer coefficient (h), Reynolds number (Re), Prandtl number (Pr), Nusselt number $(\mathrm{Nu})$, heat transfer rate...etc. have been calculated all with the properties of the air as a working fluid. A new correlation has been predicted which make easy method for predicting the thermal properties of such devices.

Also, a finned plate has been established and the input parameters were velocity of air and heat flux. Local heat transfer coefficient and Nusselt number for the heated finned plate experiencing forced convection have been measured. The data obtained have been plotted on graphs to predict the variation of theoretical and experimental Reynolds number (Re) and Nusselt number $(\mathrm{Nu})$ with a variety of oday.adnan@uod.ac 
parameters fluid velocity and heat flux.

\section{EXPERIMENTAL APPARATUS:}

\section{1: Wind tunnel:}

The measurements were controlled in an open-circle wind flow circuit in constrained draft method of a similarly low disturbance level small-scale wind tunnel. The passage structure has been designed alongside a voltage controller, heater and a heat measuring framework to quantify the impact aerodynamic forces on a body and thermal effects on boundary layer with the nearness of heat flux on the tried model. The tunnel has a $750 \mathrm{~mm}$ long test segment with square cross-area of $60 \mathrm{~mm} \mathrm{X} 40 \mathrm{~mm}$. The tests were run at various free-stream speeds with most extreme $6 \mathrm{~m} / \mathrm{s}$. Stream trap net of $5 \mathrm{~mm}$ distance across introduced at start of the main edge of the test segment to traps the boundary layer and gives a fully developed boundary layer at the test area entrance for free stream speeds that an anemometer utilized for measuring it.

Figure (1-a, and $\mathrm{b})$ demonstrates a photo and a schematic outline of the test rig. The rig have been manufactured and installed in the Mechanical Engineering department laboratories in the University of Duhok. The hydrodynamic passage length which is characterized as that piece of the channel or duct wherein the momentum boundary layer develops and the speed distribution changes with length, [Kays W. M. and Crawford M. E. (1993)]. Here we talk about fully developed velocity profile as the fixed velocity distribution in the fully evolved region. It is observed that the turbulent flow becomes hydro-dynamically and thermally fully developed after a relatively short distance from the entrance, this full development criterion is particularly applicable to fluids with Prandtl numbers of order 1, [Adrian Bejan (2013)]. Since the turbulent entrance length is much shorter than would be laminar estimate especially when $R e_{D}>2000$, it is easy to verify that $L_{D} / D_{h} \cong 10$ as a consequence of linear growth of turbulent shear layers.

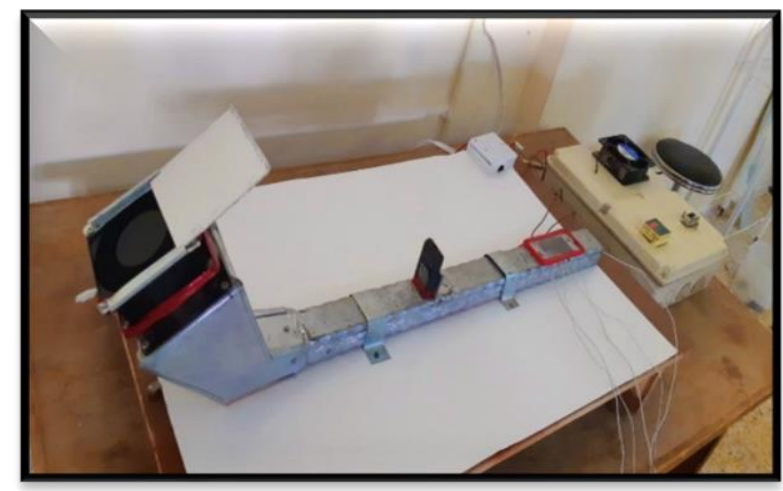

Fig. (1-a): Photograph of the test rig without insulation.

arkan.alhazeen@uod.ac; oday.adnan@uod.ac 


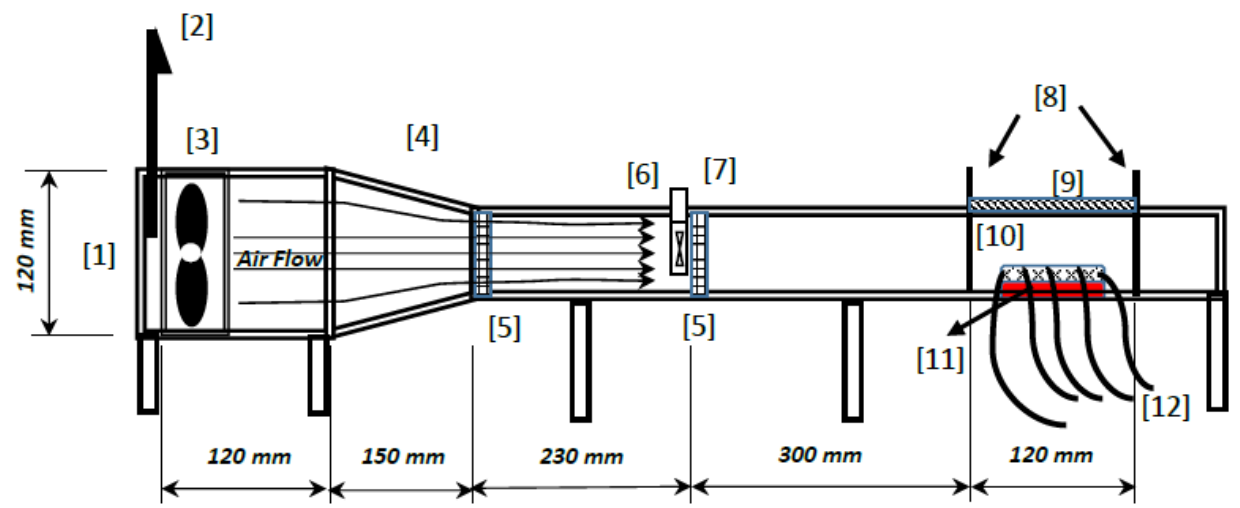

\begin{tabular}{|l|l|}
\hline No. & \multicolumn{1}{|c|}{ Part } \\
\hline$[1]$. & Input duct \\
\hline$[2]$. & Sluice gate (Flow control) \\
\hline$[3]$. & Fan \\
\hline$[4]$. & Converging duct \\
\hline$[5]$. & Flow trap (screen) \\
\hline$[6]$. & Anemometer \\
\hline$[7]$. & Free stream temperature sensor \\
\hline$[8]$. & Test section \\
\hline$[9]$. & Clear glass \\
\hline$[10]$. & Test specimen \\
\hline$[11]$. & Heater \\
\hline$[12]$. & K-Type Thermocouples \\
\hline
\end{tabular}

Fig. (1-b): Schematic diagram of the test rig

\section{2: Heat Sinks:}

The need of microelectronic gadgets cooling and the decrease in overall shape factors, thermal handling turns out to be increasingly more significant component of electronic item design. Both the performance unwavering quality and expectation of pack are conversely identified with the segment temperature of the hardware. One of the most realized heat sinks is the normal flat plate with and without fins or pin-fins. In present work, the air have been decided to be the cooling liquid, where the heat move over the interface between the solid surface and coolant air is the lead effective inside the framework, and in this manner the solid-air interface represents to the best hindrance for heat dispersal. The warmth sink utilized by and by brings down this boundary fundamentally by expanding the surface zone that is in direct contact with the coolant air. Figure (2), represent the two models of flat plate with and without fins, indicating the purposes of estimating temperature utilizing the K-Type thermocouple. (a)

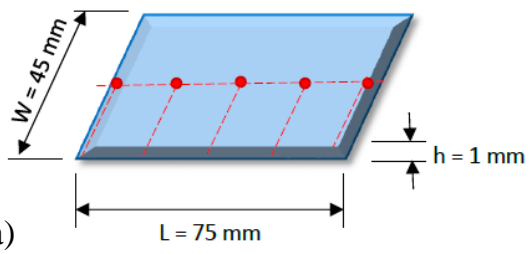

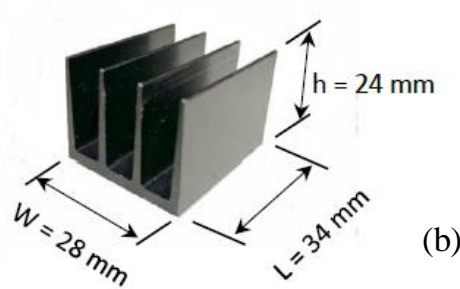

Fig. (2): a: Flat Plate. b: Finned plate

arkan.alhazeen@uod.ac; oday.adnan@uod.ac

${ }^{1}$ Corresponding author: College of Engineering, University of Duhok, Kurdistan Region, Iraq. 


\section{3: Auxiliary Equipment:}

As auxiliary devices that have been used for reinforcing the rig work properly, Voltage regulator ZKG-B used to control the applied heat flux to the heat sink by applying voltage to a high performance Triac type BTB41, which can be used for phase control of inductive and resistive load like heater. It has a built-in LED which may display output voltage, also, have high accuracy, good shock resistance, reliability and strong anti-interference ability with a compact dimensions and light weight. It is used to change the temperature of the heater by controlling the amount of power arrived to it.

The heater designed by using resistance wire (Ni chrome - Cr20Ni80) wrapped around thin film. The end of resistance wire attached to the voltage regulator in order to control the power arrival and consequently controlling the temperature of the heater. A highly calibrated K-Type thermocouples have been used for temperature measurement. The calibration curve illustrated in figure (3), the thermocouples calibrated by using a lab. Thermometer with wide range of data compared with the used thermocouples.



Fig. (3): Thermocouples K-Type Calibration curve

A portable digital anemometer from $\mathrm{La}$ Crosse Technology have been utilized. The upper end fan generates magnetic impulse with an internal electronic circuit converts into a specific wind speed. The display also indicates how strong the wind is on the Beaufort scale brief description, this multifunction anemometer provides instant data for air speed and temperature in dual level LCD display with wide measuring range of wind speed from $0 \sim 30 \mathrm{~m} / \mathrm{s}$ and temperature of $-10{ }^{\circ} \mathrm{C} \sim 45{ }^{\circ} \mathrm{C}$. The anemometer have been installed inside the duct with its LED display outside the duct as mentioned in figure (1), part no.(6).

A sluice gate has been installed at the input of the duct with precise marking for measurement of the gate opening to control the velocity of the free stream air drafted by a computer power supply fan.

\section{CALCULATION PROCEDURE}

The average Nusselt number, $\overline{N u}$ estimates the performance of a flat-plate and a finned-plate heat sinks and can be computed based on the following equation:

$\overline{N u}_{L}=\frac{\bar{h} \cdot L_{c}}{k_{a}} \quad$ And, $\overline{N u}_{D}=\frac{\bar{h} \cdot D_{h}}{k_{a}}$

Where; $L_{c}$ is the characteristic length of flat-plate, $D_{h}$ is the hydraulic diameter of the oday.adnan@uod.ac 
duct expressed as:

$D_{h}=\frac{4 \cdot \mathrm{A}}{\mathrm{P}}=\frac{2 \cdot a \cdot b}{(a+b)}$

Where; $\boldsymbol{a}$ and $\boldsymbol{b}$ are the height and width of the cross sectional area of the duct, $\bar{h}$ is the mean heat transfer coefficient in $\left(\mathrm{W} / \mathrm{m}^{2}{ }^{\circ} \mathrm{C}\right), k_{a}$ is the thermal conductivity of coolant air in $\left(\mathrm{W} / \mathrm{m} .{ }^{\circ} \mathrm{C}\right)$ which can be estimated using the film temperature $T_{f}$ in (K) for flat-plate;

$T_{f}=\frac{T_{\infty}+T_{a v g}}{2}$

Where; $T_{\infty}$ is the free upstream input air flow, and $T_{a v g}$ is the average heated plate surface temperature. And, $T_{\infty}$ for finned-plate.

In equation (1), the mean heat transfer coefficient, $\bar{h}$ is prescribed by:

\section{a. Flat-plate:}

$\bar{h}=\frac{\dot{\mathrm{Q}}}{A_{T} \cdot\left(T_{\text {avg }}-T_{\infty}\right)}$

Where; $\dot{Q}$ is the rate of heat energy transfer in a given time period (Watt). The rate of electric energy supplied to the heater is equal to the energy (heat) transfer rate from the heater to the contacted plate taking into account the losses using the efficiency of the manufactured heater. $A_{T}$, is the total area in $\left(\mathrm{m}^{2}\right)$ that subjected to the cooling air stream.

\section{b. Finned-plate:}

$\bar{h}=\frac{\dot{\mathrm{Q}}}{A_{T} \cdot T_{m}}$

Where; $\dot{Q}$ is the rate of heat energy transfer in a given time period. The rate of electric energy supplied to the heater is equal to the energy (heat) transfer rate from the heater to the contacted finned plate taking into account the losses using the efficiency of the manufactured heater.

$$
\dot{\mathrm{Q}}=\dot{m}_{a} \cdot C p_{a} \cdot\left(T_{\text {out }}-T_{\text {in }}\right)
$$

Where; $\dot{m}_{a}$ and $C p_{a}$ are the mass flow rate and specific heat of air respectively. Also;

$\dot{m}_{a}=\rho_{a} \cdot A_{c} \cdot V_{a}$

Where; $\rho_{a}$ is the inlet air density in $\left(\mathrm{kg} / \mathrm{m}^{3}\right)$, $A_{c}$ is the duct cross sectional area $\left(\mathrm{m}^{2}\right)$, and $V_{a}$ is the measured air velocity in $(\mathrm{m} / \mathrm{s})$. Also, $A_{T}$ is the total area of the fins and is given as follows:

$\mathrm{A}_{T}=\mathrm{W} \cdot \mathrm{L}+2 \cdot H \cdot(L+t) \cdot N_{f}+2 \cdot B \cdot(L+W)$.

Where; $W$ and $L$, are the width and length of the heat sink respectively, $N_{f}$ is the number of fins, $H$, $t$, and $B$ are the height, thickness of fins and the base height respectively, [Ammar A., et. al., (2019)].

Also, $T_{m}$ is the logarithmic mean temperature and can be expressed as:

$\mathrm{T}_{m}=\frac{\left(T_{\text {out }}-T_{\text {in }}\right)}{\log _{e}\left(\frac{T_{S}-T_{\text {in }}}{T_{S}-T_{\text {out }}}\right)}$

Where; $T_{\text {in }}$ is the free upstream input air flow, and $T_{S}$ is the base surface temperature of the fin. c. Measuring bulk air temperature downstream $\left(T_{\text {out }}\right)$ and surface wall temperature $\left(T_{s}\right)$ :

In general, the accuracy of the experimental results is governed by the accuracy of the individual measuring instruments. For the present experiments, due to the heat source on one side, the air temperature in the duct downstream of the heated surface may not be even across the duct, giving a temperature profile across the duct and a variation in $\boldsymbol{T}_{\text {out }}$, [TD1005-TQuip., (2015)]. Figure (4) shows the temperature profile and temperature measuring probe position. 


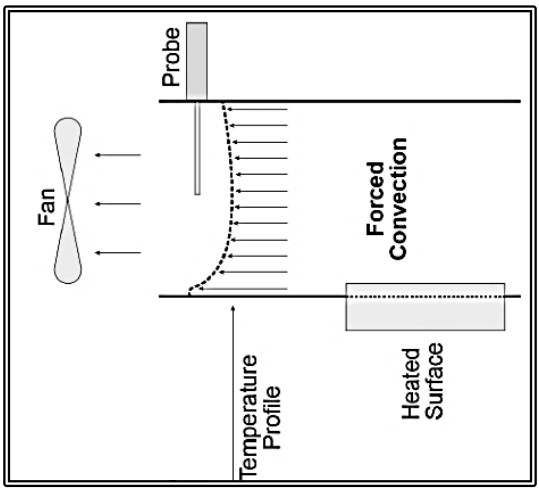

FiG. (4): Temperature profile and measuring probe position.

A single point measurement of downstream temperature may not give an accurate value for the bulk temperature of the air. The theory and experiments show that the extended surfaces give a thermal gradient along their length which will transfer to the air passing over them and therefore downstream the duct. The geometry, thermal conduction of the extended surfaces and the air velocity all affect the temperature profile, [Holman, J. P. (2010)]. However, the downstream probe allows a traverse across the duct so simple averaging or integration of the temperature values give sensible values of $\left(\boldsymbol{T}_{\text {out }}\right)$. Also, the accuracy of the surface wall temperature $\left(\boldsymbol{T}_{s}\right)$ have been validated by drawing the experimental measurement versus the estimated theoretical one. Figure (5) represent the experimental accuracy of surface wall temperature measurement.

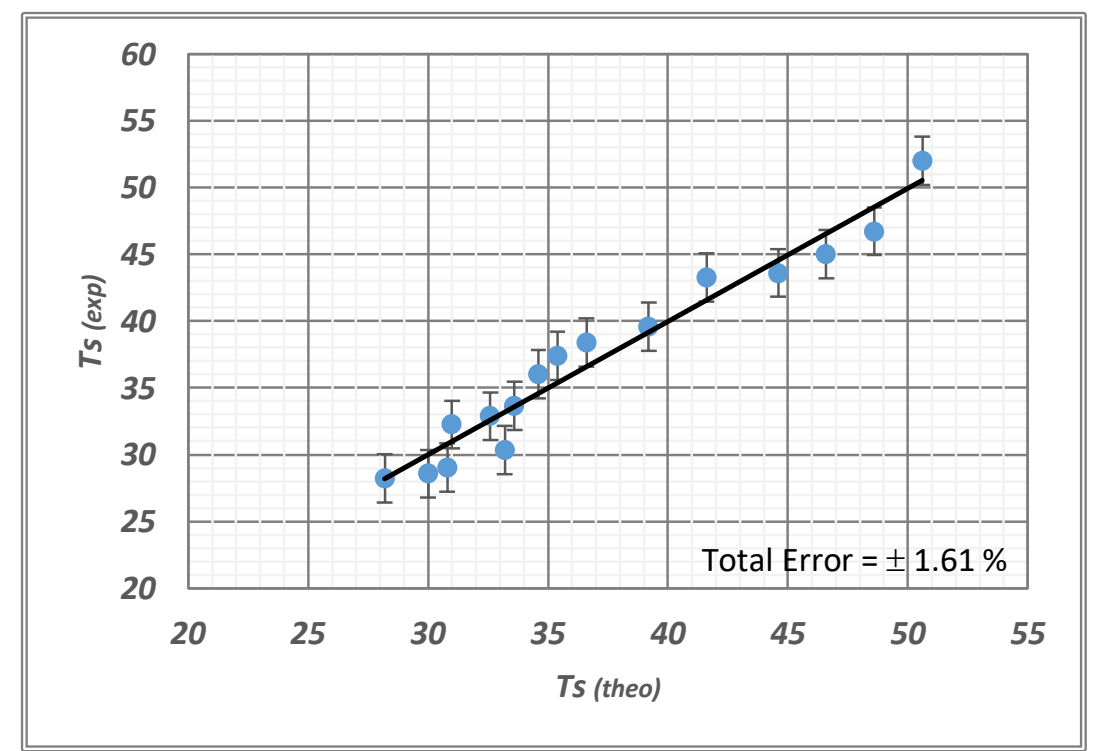

Fig. (5): Experimental accuracy of surface wall temperature.

arkan.alhazeen@uod.ac; oday.adnan@uod.ac 


\section{RESULTS AND DISCUSSION}

\subsection{Flat-plate heat sink:}

The primary objective of the present work is to validate the small-scale wind tunnel that have been designed for experimental researches of a mini and micro heat sink objects that could be used in electronic, and biomedical equipment. The local heat transfer coefficient and Nusselt number have been measured for a heated flat-plate experiencing forced convection cooling. The flat-plate consisted of a smooth aluminum rectangular surface, as shown

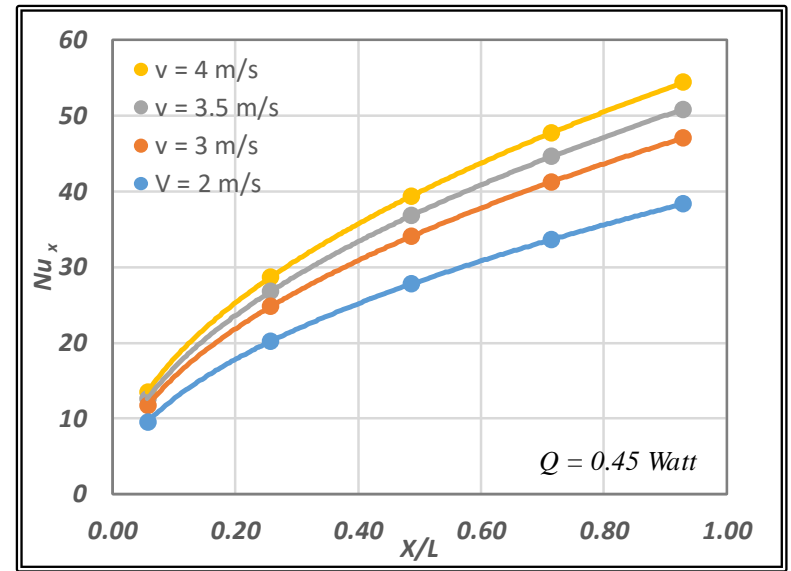

(a)

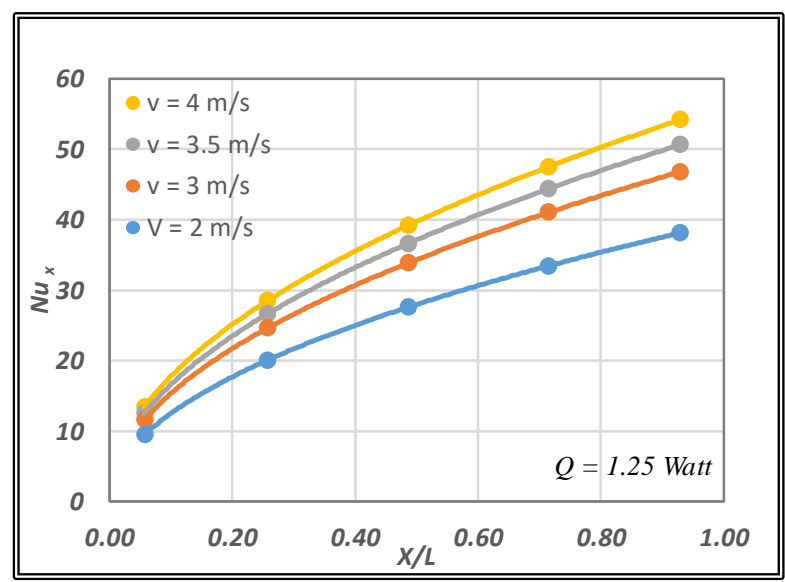

(c) previously in figure (2).

\subsubsection{Local $\left(N u_{x}\right)$ number and heat transfer coefficient (h):}

Local Nusselt number have been calculated using equation (1) as a function of the distance from the leading edge of the flat-plate. By changing the input voltage within a range (15 to 30 step 5) Volt and hence changing the heater power, the change in local Nusselt number varying with the distance $(\boldsymbol{X} / \mathbf{L})$ with a velocity range (2 to 4$) \mathrm{m} / \mathrm{s}$ shown in figures (6).

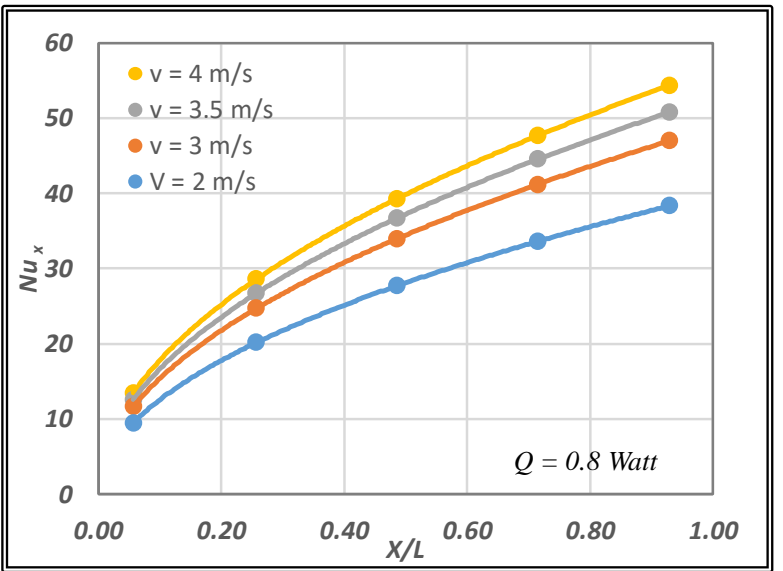

(b)

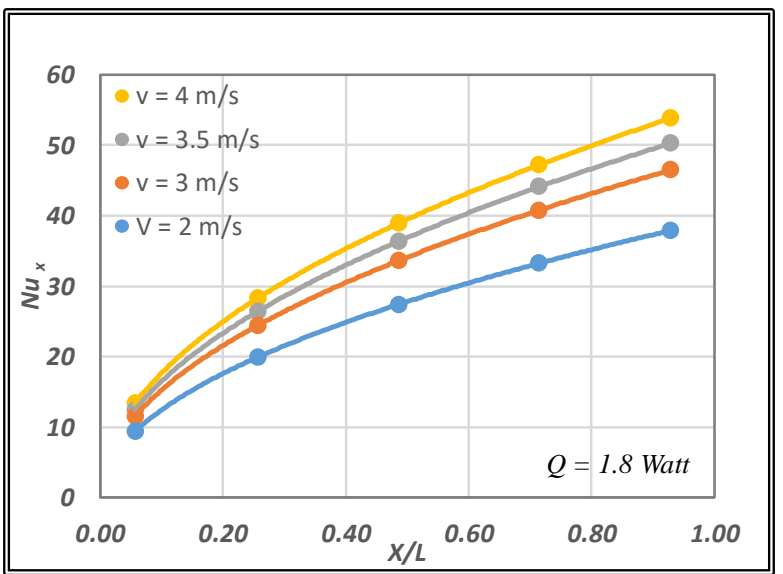

(d)

Fig. (6): Local Nusselt number along the distance $X / L$ with variable air velocity for different electric input power.

arkan.alhazeen@uod.ac; oday.adnan@uod.ac 
As expected, since the used flat-plate is a mini smooth flat-plate, the convection heat transfer rate will increase till it reaches the end of the plate. This is due to the fact that a small surface area will yield to insufficient time for the mini plate to retain the heat especially that input power is low. Moreover, as the velocity increases, the rate of heat transfer will increase due to the increase in the heat transfer coefficient which yield to the increase in local Nusselt number. The variation of the heat transfer coefficient with flow velocity can be noticed in figure (7) which illustrate the difference between the experimental and theoretical heat transfer coefficient. This difference is basically due to the uncertainty in the measurement devices and the unaccounted losses like radiation.

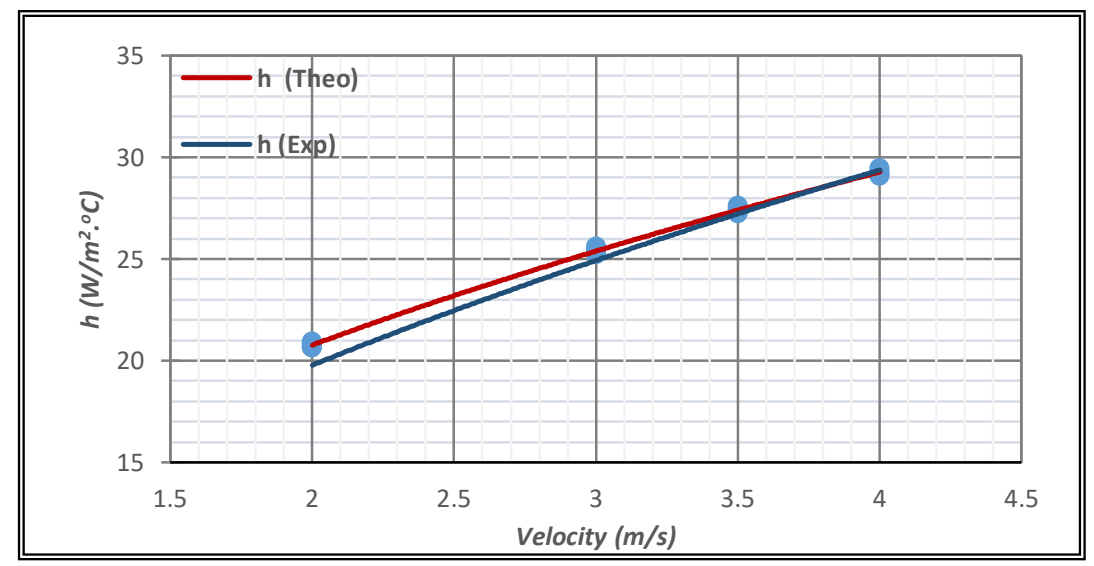

Fig. (7): Heat transfer coefficient as a function of flow Velocity

\subsubsection{Average $\left(\overline{N u}_{L}\right)$ number:}

The average heat transfer coefficient is often evaluated by performing integration along the flat plate length, if Prandtl number is assumed constant along the plate. The integration results to the following [Holman, J. P. (2010)]:

$\overline{N u}_{L}=2 . N u_{X}$

Churchil, et.al. as mentioned by Shang, D. (2011), for a constant heat flux correlated an expression for the Nusselt number as a function Reynolds and Prandtl numbers:

$N u_{X}=\frac{0.886 * \operatorname{Re}_{X}^{1 / 2} * \operatorname{Pr}^{1 / 3}}{\left[1+\left(\frac{\operatorname{Pr}}{0.0207}\right)^{2 / 3}\right]^{1 / 4}}$

Also, McQuiston, et. al. (2005), mentioned that Colburn presented an analogy for correlating forced convection heat transfer with uniform heat flux over a flat-plate, as follows:

$$
\overline{N u}_{L}=0.0366 *\left(\operatorname{Re}_{L}^{0.8}\right) *\left(\operatorname{Pr}^{1 / 3}\right)
$$

Figure (8) presents the Experimental and theoretical average Nusselt number compared with the previously published researches and a good compatibility have been gained from comparison. As a validation for the present work, a new correlation has been established as an average of the present and previously published works expressed as follows:

$\overline{N u}_{L}=C_{1} *\left(\operatorname{Re}_{L}^{C_{2}}\right) *\left(P r^{C_{3}}\right)$

Where; $C_{1}, C_{2}$, and $C_{3}$ are empirical constants obtained from least squares approximation [Gerald C. F., and Wheatley P.O.(2004)], fitted with an uncertainty of $\pm 5 \%$, where $C_{1}=0.3796$, $C_{2}=0.545$, and $C_{3}=0.2$ for $\operatorname{Pr}<1.0$.

arkan.alhazeen@uod.ac; oday.adnan@uod.ac 


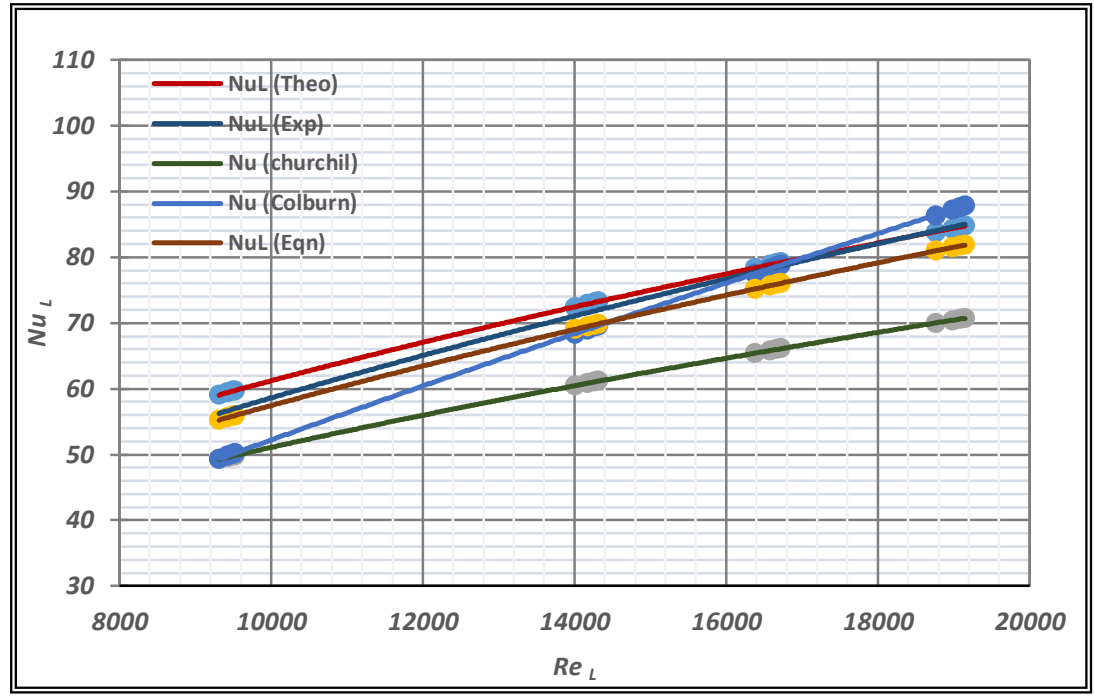

Figure (8): Average Nusselt number as a function of Reynolds number for a flat-plate with uniform heat flux.

\subsection{Finned-plate heat sink:}

After validating the small-scale wind tunnel designed for experimental researches of a mini and micro heat sink forms by using a smooth flat-plate, and differentiating equation that correlates the average Nusselt number with Reynolds and Prandtl numbers. A trial has been experienced with a mini finned-plate to be more convenient and familiar with the rig. The specimen has been expressed in figure (2).

\subsubsection{Heat Transfer rate:}

Figure (9) presents the heat transfer rate as a function of Reynolds number. One can notify that as the mass flow rate increases (with velocity range 2 to $6 \mathrm{~m} / \mathrm{s}$ ) which results in increase in Reynolds number, the rate of heat transfer increases for a voltage range (30 to 60 volt step 5) specified input power irrespective fin type. The heat transfer enhancement in fin array is achieved by introducing turbulence.



Fig.(9): Heat transfer rate as a function of Reynolds number for different voltage input power

arkan.alhazeen@uod.ac; oday.adnan@uod.ac 
As a result of increasing the flow velocity, the difference between the input free stream temperature and fin surface temperature is decreases. This is fact that the forced convection helps improve heat transfer. The results showed a decreased gradient forced convection and lower overall temperatures along the extended surfaces, which yield cooler surfaces at any given air velocity. This is expressed in figure (10).

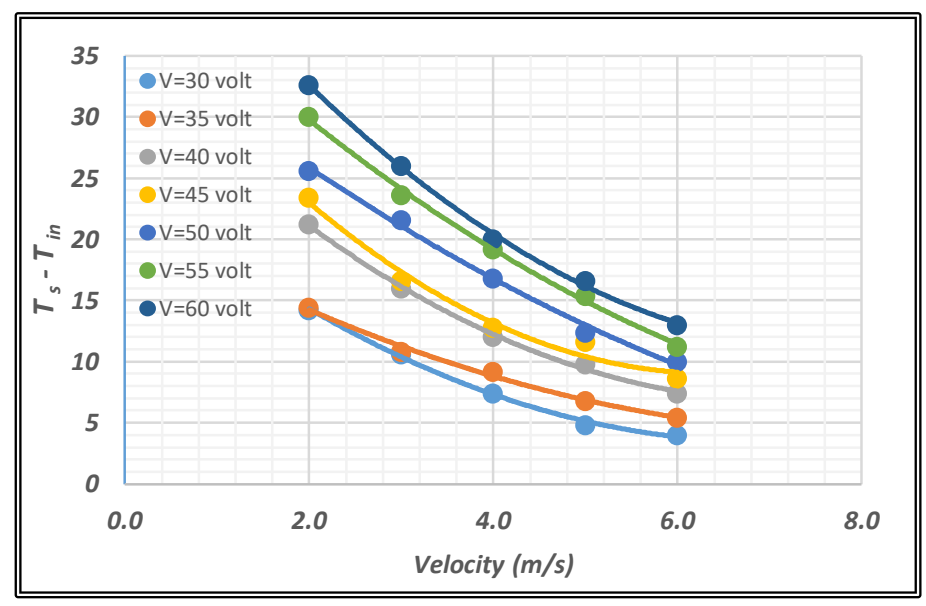

Fig. (10): Temperature difference as a function of Velocity for different voltage input power

\subsubsection{Heat Transfer coefficient $(h)$ :}

In general, the thermal resistance is characterized as the temperature difference between the heat sink base temperature at the outlet and fluid bulk mean temperature at the inlet per unit heat flow rate, this can be seen from figure (10). Subsequently, the heat transfer coefficient $(h)$ increases as the velocity increases which means increasing in cooling effect across the fin array. Figure (11) presents the experimental heat transfer coefficient varying with the theoretical one for a wide variety of the rig velocity.

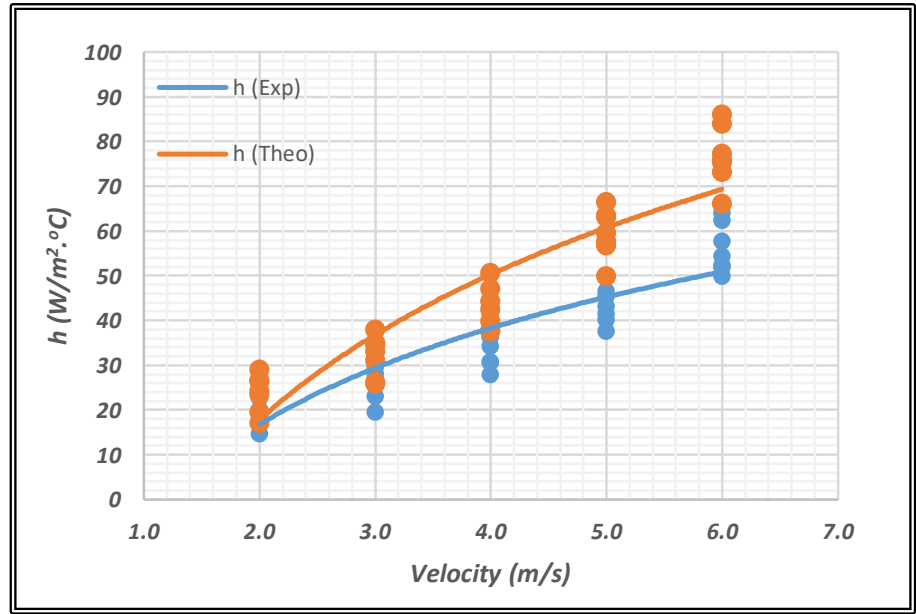

Fig. (11): Heat transfer coefficient as a function of velocity. Comparison of experimental and theoretical results

arkan.alhazeen@uod.ac; $\quad$ oday.adnan@uod.ac 


\subsubsection{Average Nusselt number $\left(\overline{N u}_{D}\right)$ :}

Ugur A. and Kadir B. (2006) directed a test examination of the heat transfer and friction loss characteristics in a horizontal rectangular channel appended with a rectangular blade over one heated surface. Their work demonstrated the rectangular fins with and without perforation. The empirical correlation for non-hollow rectangular fins can be illustrated as follows:

$\overline{N u}_{s}=0.419 *\left(R e_{s}^{0.565}\right)$

$f_{s}=0.002 *\left(R e_{s}^{0.4}\right)$

This could be applicable for smooth channel with $\pm 3.2 \%$ error.

Kavita, et.al. (2014) reported an experimental study to investigate the forced convection heat transfer enhancement over horizontal flat surface with rectangular fin arrays with/without Lateral Square and circular perforation. The correlation expressed as:

$\overline{N u}_{s d}=0.015 *\left(R e_{s}^{0.816}\right)$
The equation is valid for Reynolds number range from $2.1 \times 10^{4} \leq R e \leq 8.7 \times 10^{4}, 200 \mathrm{~W}$ heat input

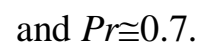

In present work, the experimental average Nusselt number were conducted against theoretical one and compared with the previously published works taking into consideration the boundary conditions of their application to coincide with the present experiment. Figure (12), demonstrates the present and published correlations compared with the empirical equation that have been differentiated depending on the average of all correlations using least squares approximation [Gerald C. F., and Wheatley P.O. (2004)]. The conducted equation can be illustrated as follows: $\overline{N u}_{D}=0.0268 *\left(R e_{D}^{0.8475}\right)$

The equation is valid for Reynolds number range from $7 \times 10^{3} \leq R e \leq 22.5 \times 10^{3}$, and $P r<1.0$. This could be applicable within an error $\pm 6.4 \%$. $f_{\text {sd }}=0.001 *\left(R e^{0.344}\right)$

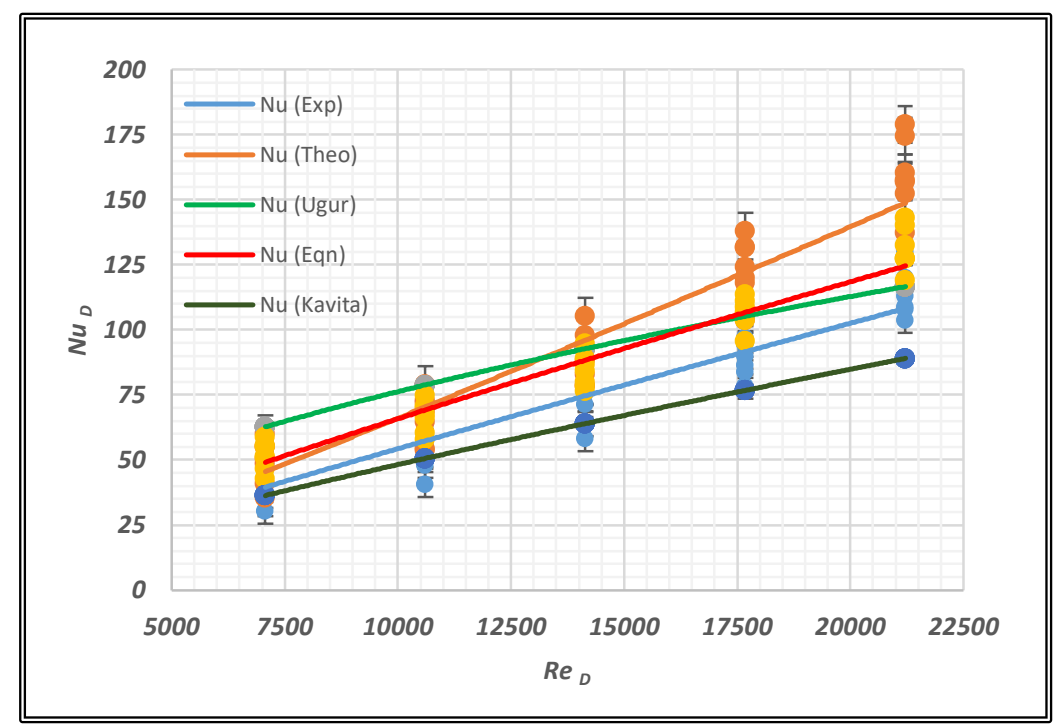

Fig.(12): Experimental and differentiated correlations compared with theoretical and published researches.

\subsubsection{Fin Performance:}

To evaluate the effectiveness of the tested finned plate, it is useful to search out the fin performance. The ratio of the actual heat transfer rate from the finned plate $\left(Q_{f}\right)$ possessing arkan.alhazeen@uod.ac; convection heat transfer coefficient and average surface temperature to the heat transfer rate without fins at base temperature $\left(Q_{f s}\right)$.

$$
\varepsilon_{f}=\frac{\left(Q_{f}\right)}{\left(Q_{f s}\right)}
$$


Figure (13) shows that as Reynolds number increases, fin effectiveness decreases. Since the effectiveness is higher than unity, it reveals that the use of fin arrays has an advantage on the basis of heat transfer enhancement.

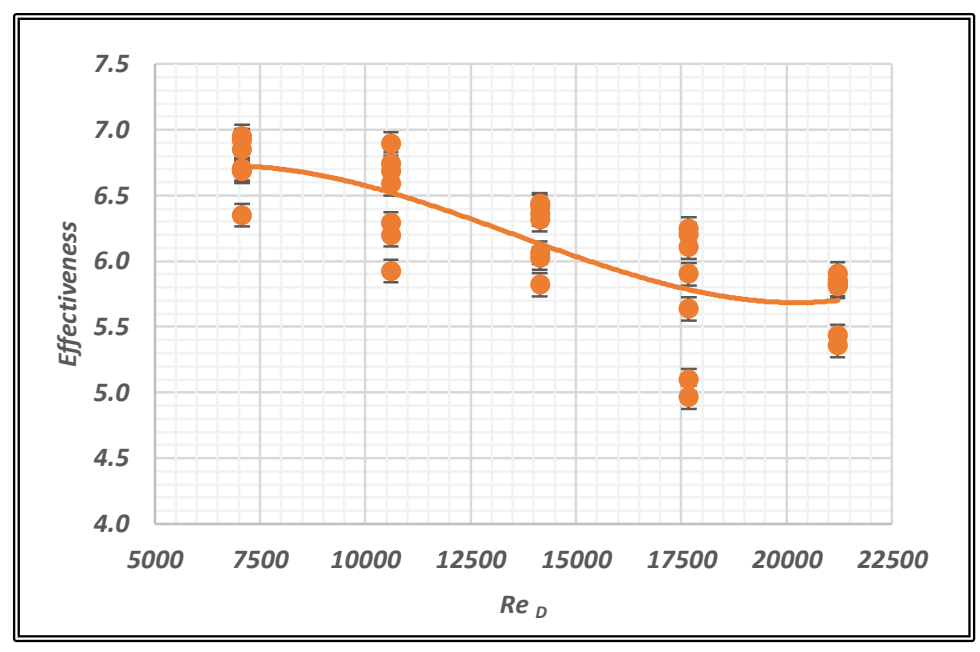

Fig. (13): Performance of finned plate effectiveness with Reynolds number.

\section{CONCLUSION}

- In present work, a small-scale wind tunnel has been implemented patriotically for the use of scientific researches. The validity of the design has been achieved by investigating a primary flat plat heat transfer by forced convection, with an acceptable result that have been compared with previously published.

- An empirical correlation for a flat-plate have been differentiated depending on the experimental, theoretical and a previously published results.

- For more conviction, investigation have been done on a mini fin arrays with triangular cross sectional area. An empirical correlation has been obtained which demonstrated a good results compared with the previously published works.

- Finally, it is worth to mention that the present rig can be used for future work in finding hydraulic and thermal performance of different mini heat sink objects. It is suggested that the heat transfer enhancement with respect to various cross-sectional area of fins, different arkan.alhazeen@uod.ac; distances in span wise directions, and the gap effect with fillets between the fins in future work.

\section{REFERENCES}

Satish G. Kandlikar, Srinivas Garimella, Dongqing Li, Stéphane Colin and Michael R. King, "Heat Transfer and fluid flow in mini-channels and micro-channels", Copyright (C) 2006 Elsevier Ltd., (2006).

Bahrami, M., Yovanovich, M. M., and Culham, J. R., "Pressure Drop of Fully Developed Laminar Flow in Microchannels of Arbitrary Cross-Section", Transactions of the ASME, Journal of Fluids Engineering, Vol (128): 1036-1044, (2006).

Mahgoub, S. E. "Forced convection heat transfer over a flat plate in a porous medium", Ain Shams Engineering Journal, www.elsevier.com/asej, 4: 605-613, (2013).

Md. Emran and Mohammad Ariful Islam, "Numerical investigation of flow dynamics and heat transfer characteristics in a oday.adnan@uod.ac ${ }^{1}$ Corresponding author: College of Engineering, University of Duhok, Kurdistan Region, Iraq. 
microchannel heat sink",

Procedia-Engineering, 90: 563-568, (2014).

Vedulla Manoj Kumar, Sk. Farooq, and B Nageswara Rao, "A Review of Microchannel heat sink", Australian Journal of Basic and Applied Sciences, 10(9) May, pp. 230-238, (2016).

Kays W. M., and Crawford M. E., "Convective Heat and Mass Transfer", McGraw-Hill, Inc.,

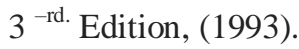

Adrian Bejan, "Convection Heat Transfer", John

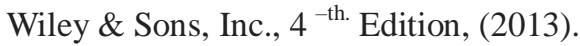

Ammar A. Hussain, Basima F., Basima S. K., and Hossein T., "Numerical Investigation of heat transfer enhancement in plate-fin heat 11]: Effect of flow direction and fillet profile", Case Studies in Thermal Engineering Journal, (13): I00388, ELSEVIER, (2019).

TD1005 "Engineering Excellence in Education: Free and Forced Convection", User guide, TecQuipment, Ltd., UK, (2015).

Holman J. P., "Heat Transfer", McGraw-Hill, Inc., $10^{\text {th. }}$ Edition, (2010).
Shang, D., "Theory of Heat Transfer with Forced Convection Film Flows", Heat and Mass Transfer: Series Editors, Springer-Verlag Berlin Heidelberg, (2011).

McQuiston, F. C., Parker, J. D., Spitler, J. D.," Heating, Ventilating, and Air Conditioning: Analysis and Design", Trans. John Wiley \& Sons, Inc., $6^{\text {-th }}$ Edition, (2005).

Gerald C. F., and Wheatley P. O., "Applied Numerical Analysis", PEARSON, Inc., $7^{\text {-th. }}$ Edition, (2004).

Ugur Akyol, Kadir Bilen,'Heat transfer and thermal performance analysis of a surface with hollow rectangular fins", Applied Thermal Engineering, vol. 26, pp, 209-216, ELSEVIER, (2006).

Kavita, H. D., Vivek, K. S., Hanamant, S. D.,'Thermal Analysis of Square and Circular Perforated Fin Arrays by Forced Convection”, Int. J. of Current Engineering and Technology, pp, 109-114, INPRESSCO, (2014).

arkan.alhazeen@uod.ac; oday.adnan@uod.ac 